\title{
Environmental evaluation with chemical sensors in the Palace Museum of Wilanów
}

\author{
J. PENA-POZA ${ }^{1}$, M. GARCIA-HERAS ${ }^{1}$, T. PALOMAR ${ }^{1}$, A. LAUDY ${ }^{2}$, E. MODZELEWSKA ${ }^{2}$, \\ and M.A. VILLEGAS ${ }^{1 *}$ \\ ${ }^{1}$ Instituto de Historia, CCHS-CSICC. Albasanz, 26-28. 28037 Madrid, Spain \\ ${ }^{2}$ Wilanów Palace Museum, 10/16 Stanislawa Kostki Potockiego St., 02-958 Warsaw, Poland
}

\begin{abstract}
Environmental evaluation arises as an innovative procedure to carry out preventive conservation of Cultural Heritage items. Parameters contributing to the proper conservation of such items can be monitored and assessed. Chemical sensors with optical response synthesised by the sol-gel method are useful for a complete and accurate environmental evaluation. Physical-chemical mechanisms of decay and degradation of materials can be predicted from the sensors response, which will favour the decisions on the adequate procedures to avoid damage. Sol-gel sensors prepared and applied in the present work are reversible, reusable and regenerable. Their optical response provides a change of colour vs. the parameters to which they are sensitive.

Both temperature and environmental acidity have been monitored in several selected chambers of the Palace Museum of Wilanów (Warsaw, Poland). The optical response of sensors was recorded by visible spectrophotometry from June 2010 to December 2010 . The results inform on the environmental conservation conditions, both indoor and outdoor the Palace. Main innovation of the research carried out concerns the evaluation of the environmental acidity as an essential parameter to be taken into account for the proper conservation that can not be measured by conventional methods.
\end{abstract}

Key words: heritage, sensor, acidity, temperature, sol-gel, Wilanów.

\section{Introduction}

Deterioration of Cultural Heritage items has been accelerated during the last decades. This is due to several factors: industrial development, increase of emissions to the atmosphere, appearance of new pollutants, etc. To avoid damage, urgent preventive conservation actions should be taken. Not only the items exposed to outdoor weathering are affected by changes of humidity, temperature, light and pollutants, but also those exhibited or stored indoor. Heritage items conserved indoor are also exposed to pollutants action as dangerous as that of the outdoor atmosphere, e.g. condensation, microorganisms, smoke, woods emissions, etc.

Preventive conservation takes into account several tendencies and methodologies for Heritage items protection. The objective is to predict damage agents that can or could be the origin of a progressive deterioration. Once the possible damage is evaluated and quantified, adequate technologies and methods will be selected to avoid decay. In other words, materials, devices or procedures should be found out to favour preventive conservation. In this stage new technologies based on environmental control and sensing are useful [1, 2].

The present work has been carried out in the Palace $\mathrm{Mu}$ seum of Wilanów (Warsaw, Poland), in which environmental acidity and temperature sensors have been installed. The sensors have been prepared by the sol-gel procedure and are able to evaluate the acidity degree of the air $(\mathrm{pH})$ [3] and the local temperature both indoor and outdoor. Wilanów Palace is lo- cated in SE Warsaw. It was built in the $18^{\text {th }}$ century baroque style and is known as the Polish Versailles. The palace is out of downtown Warsaw and survived almost intact to the World War II. Nowadays Wilanów Palace is a museum including the 45 ha park in the surroundings. The baroque, rococo and classic styles can be observed indoor through many valuable and interesting items as sculptures, paintings, furniture, lamps, stoves, weapons, clothing, ornamental and tableware objects, specific collections, etc.

The objectives of the present work focus, on the one hand, on the synthesis of environmental optical sensors of acidity and temperature by the sol-gel process, and on the other hand, on the evaluation of the conservation conditions in the Wilanów Palace. The results will provide scientific bases to apply, if necessary, control procedures to ensure the proper preventive conservation of the Cultural Heritage items in the Palace Museum.

\section{Experiments}

2.1. Synthesis of sensors. Environmental acidity sensors consist on a thin coating prepared by the sol-gel method and deposited upon a common glass slide piece [3] (Fig. 1). The sensitive coating is obtained from a sol or colloidal suspension in which an organic dye that behaves as sensitive phase is encapsulated [4]. The organic dye $\left(3^{\prime}, 3^{\prime \prime}\right.$ dichlorophenolsulfonephthalein) was selected according to the $\mathrm{pH}$ range to which Cultural Heritage items are usually exhib-

*e-mail: mariangeles.villegas@cchs.csic.es 
ited or stored, i.e. near the neutral conditions at $\mathrm{pH}$ between 6 and 8 , approximately. Once the glass slide is coated by the sol (dip-coating method), they are partially densified up to $60^{\circ} \mathrm{C}$. This step ensures the chemical stability of the sensor. After the heat-treatment the thin coating (gel) reaches $250-450 \mathrm{~nm}$ thickness and coats both sides of the glass substrate. The soobtained sensors show good thermal and chemical resistance in a wide temperature range (from -10 to $60^{\circ} \mathrm{C}$, approximately) during long exposure periods [5].

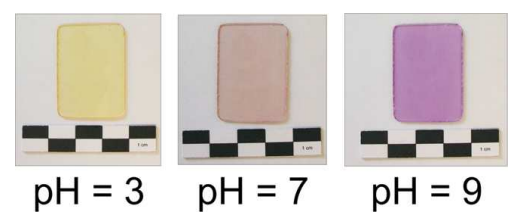

Fig. 1. Aspect of an environmental acidity sensor sensitised at different $\mathrm{pHs}$

The temperature sensors (Fig. 2) were synthesised in a similar way in respect to the sol preparation. In this case, the sensitive phase is a coordination complex of Co (II) [6]. Depending on the relative proportions of the Co (II) complex and other components of the sol, it is possible to obtain temperature sensors with different sensitivity range. Two different temperature sensors were prepared (namely T5 and T6) to be used indoor and outdoor, respectively. In each case the fresh prepared sol is cast in polymeric spectrophotometric cuvettes and immediately sealed with a hermetic cap. The cuvettes with the sol are maintained at room temperature $\left(\sim 20^{\circ} \mathrm{C}\right)$ during several days up to the gelling of the sol. The hermetic sealing of the cuvettes is the main factor to preserve the lifetime service of the temperature sensors.
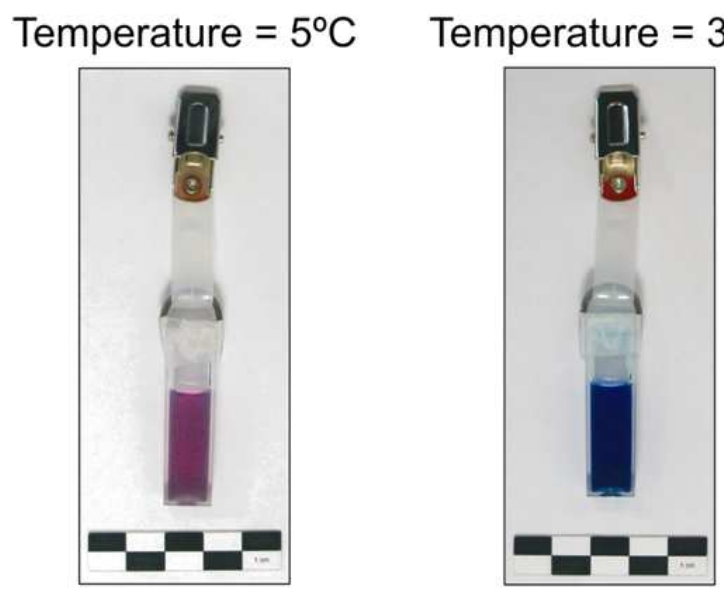

Fig. 2. Aspect of an environmental temperature sensor sensitised at different temperatures

2.2. Calibration of sensors. Both acidity and temperature sensors are chemical sensors with an optical response. This means that sensors change their colour when the corresponding environmental parameter changes. Therefore, the visible absorption spectra of the sensitive phases can be measured as a calibration variable. Visible absorption spectra of sensors were recorded with a Lovibond Spectro Direct spectrophotometer in the 330-900 nm wavelength range. Figure 3 shows several visible absorption spectra of an acidity sensor immersed to different $\mathrm{pH}$ values provided by the corresponding buffered solutions. Figure 4 shows different visible absorption spectra of a temperature sensor thermally stabilised in a climatic chamber (Dycometal, model CCM-25/81, accuracy $\left.\pm 0.01^{\circ} \mathrm{C}\right)$ at such temperatures.

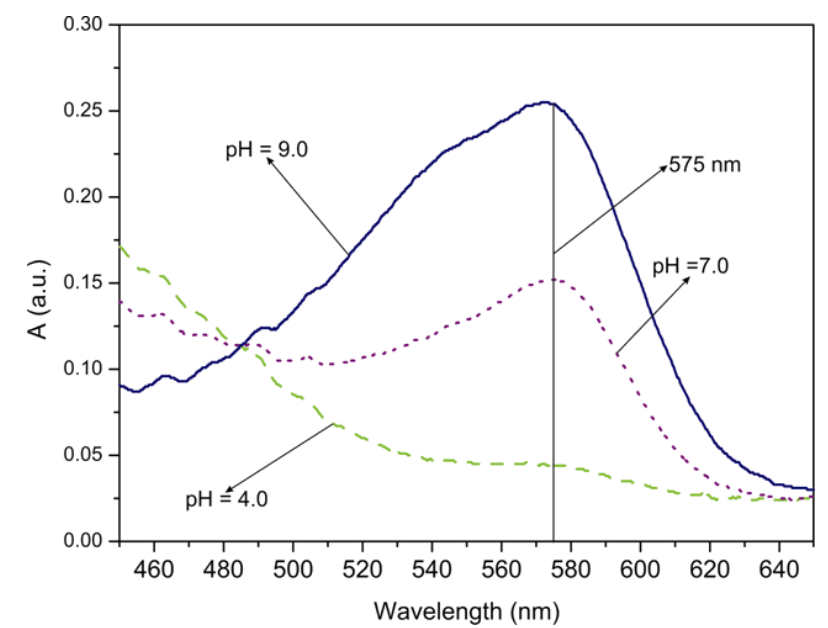

Fig. 3. Some visible absorption spectra of an acidity sensor sensitised at different $\mathrm{pHs}$

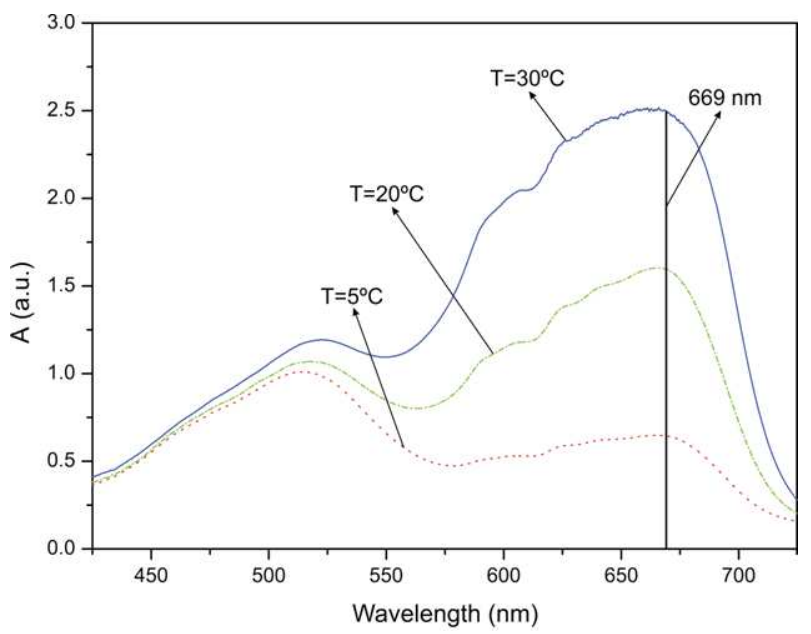

Fig. 4. Some visible absorption spectra of a temperature sensor (T5) sensitised at different temperatures

Calibration curves of acidity sensors (Fig. 5) and temperature sensors (Fig. 6) were built from the corresponding visible absorption spectra. Acidity sensors were dipped into different buffered solutions (Hydrion Buffer Salt, Aldrich) for 10-15 min and then the visible absorption spectra were recorded. The main absorption band at $\lambda=575 \mathrm{~nm}$ was selected and the corresponding intensity at this wavelength of each spectra was plotted against $\mathrm{pH}$ (Fig. 5a). The $\mathrm{pH}$ range to be monitored for conservation of Cultural Heritage items is at about 5-8, thus, the calibration for such $\mathrm{pH}$ range was fitted to a linear function (Fig. 5b):

$$
y=0.049 x-0.213 \quad R=0.9992 .
$$


a)

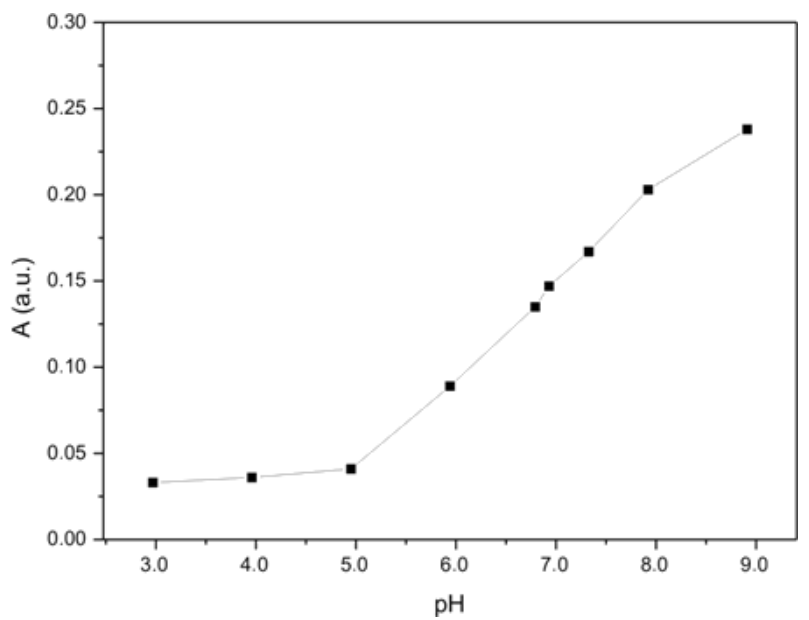

b)

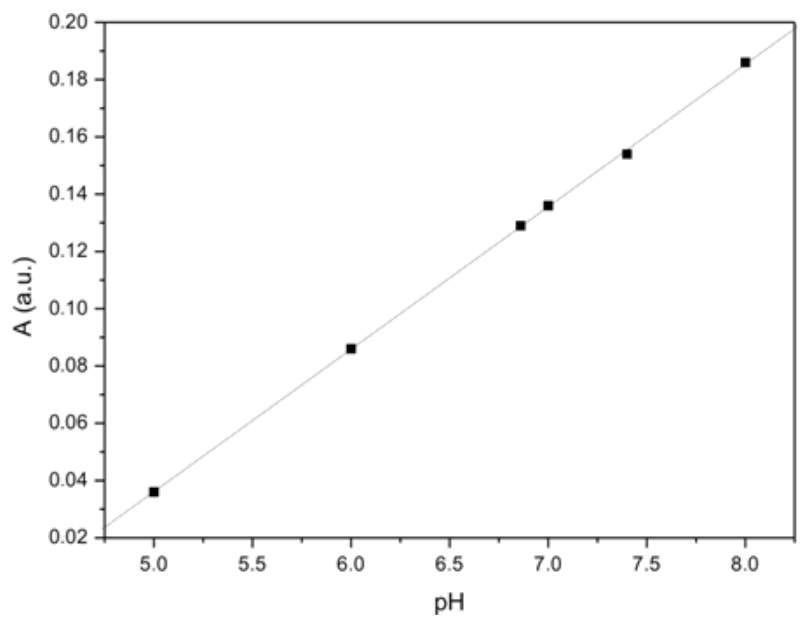

Fig. 5. a) Calibration curve for acidity sensors in the whole $\mathrm{pH}$ range, b) calibration for acidity sensors in the range $\mathrm{pH}=5-8$, fitted to a linear function

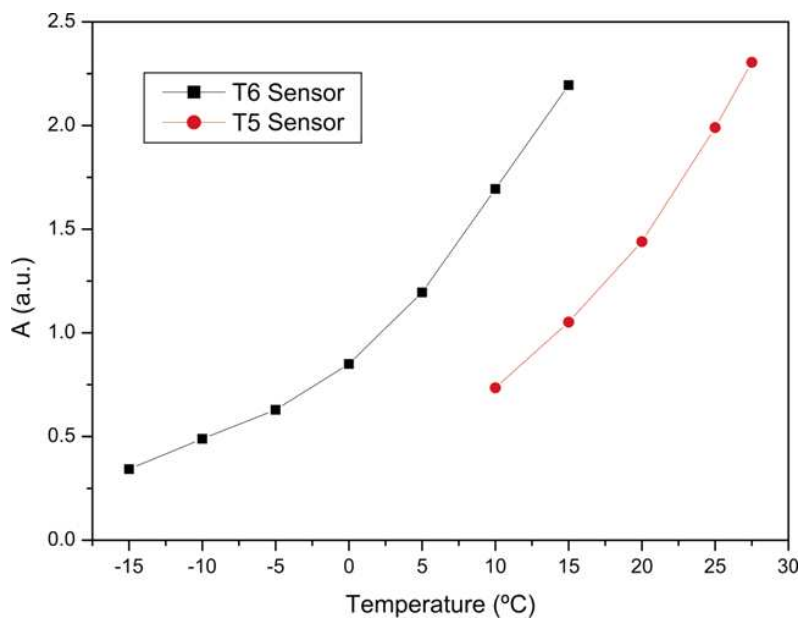

Fig. 6. Calibration curves for temperature sensors (indoor T5 and outdoor T6)

Calibration curves for both T5 and T6 temperature sensors were built (Fig. 6). The sensors were introduced in a climatic chamber and stabilised for each test temperature for
10-15 min. After each run the sensor absorption spectrum was recorded. The main absorption band at $\lambda=669 \mathrm{~nm}$ was selected and the intensities at such wavelength for each temperature were plotted and fitted to second degree functions, for T5 and T6 sensors, respectively:

$$
\begin{aligned}
& y=2.4010^{-3} x^{2}-7.2110^{-4} x+0.508 \quad R=0.9997, \\
& y=1.8210^{-3} x^{2}-6.0910^{-2} x+0.875
\end{aligned}
$$

2.3. Conditioning of sensors. The sensors response optimisation was carried out by means of a previous conditioning to maximise the optical signal and to reduce the response time [7]. For acidity sensors the conditioning process consisted to dip them in a buffered solution of $\mathrm{pH}=7.00 \pm 0.02$ at $25^{\circ} \mathrm{C}$, since the neutral $\mathrm{pH}=7.00$ is considered to be the theoretical optimal $\mathrm{pH}$ for conservation of Heritage items. The temperature sensors' conditioning can be (but not necessarily) carried out introducing them in a conventional refrigerator at about $5{ }^{\circ} \mathrm{C}$. So that, once installed indoor, they are sensitised up to room temperature in such a way that the change of colour is visible by the human eye. In general, conditioning of sensors is not necessary to be periodically done, since sensors are able to be sensitised reversibly and continuously.

To avoid some anticipated sensing of the sensors during transport from the laboratory to the test positions selected for evaluation, the acidity sensors were conserved in plastic bags hermetically closed, and temperature sensors were conserved in isothermal polymeric containers (boxes).

2.4. Sensors' installation and recording of the optical response. Several rooms of the Palace Museum of Wilanów were selected to be monitored. In each room 2 or 3 indoor test positions were assigned. Table 1 summarises the features concerning rooms, orientation and sensor positions. In each room the test positions were distributed in such a way that the sensors cover all the room area with the aim to record the environmental conditions of the most distant points of the same room. In each test position a pair of sensors, one of environmental acidity and one of temperature, were placed at a distance of $5 \mathrm{~cm}$ between them, approximately. Data were collected from June $14^{\text {th }} 2010$ to December $23^{\text {th }} 2010$.

Table 1

Rooms, orientation and test positions of sensors

\begin{tabular}{cccc}
\hline \hline \multirow{2}{*}{ Room name } & \multirow{2}{*}{ Façade orientation } & \multicolumn{2}{c}{ Sensor position (nr.) } \\
\cline { 3 - 4 } & & Indoor & Outdoor \\
\hline Lubomirski & South & $1.1,1.2,1.3$ & 4.1 \\
\hline Sypialnia królowej & West & $2.1,2.2$ & 4.2 \\
\hline Karmazynowy & North & $3.1,3.2,3.3$ & 4.3 \\
\hline
\end{tabular}

The results recording was carried out with the same apparatus with which the calibration curves were built (spectrophotometer Lovibond Spectro Direct). This is a small portable equipment that can be used in situ and transported from room to room in the Palace Museum. The data measured from sensors were stored in the spectrophotometer and then they were transferred to a conventional PC. Finally, an adequate data 
sheet containing the calibration functions makes calculations and gives the results of $\mathrm{pH}$ and temperature.

\section{Results}

3.1. Environmental acidity. The $\mathrm{pH}$ values recorded were obtained by means of the linear function fitted in the $\mathrm{pH}$ range between 5 and 8 (Fig. 5b), in which environmental pH data are expected. Such linear fit allows determining $\mathrm{pH}$ values with an accuracy of $\pm 0.02 \mathrm{pH}$ units. Each datum of environmental $\mathrm{pH}$ was obtained from Fig. $5 \mathrm{~b}$ by calculation of the corresponding $\mathrm{pH}$ for each absorption intensity at $\lambda=575 \mathrm{~nm}$ recorded from the sensors' response. Such absorption intensities were measured with the spectrophotometer mentioned in Subsec. 2.2. Figure 7 shows average values of the environmental $\mathrm{pH}$ detected by sensors in the different test positions of the monitored rooms of the Palace. The experimental symbols draw in Fig. 7 represent the average results of the measurements carried out from June 2010 to December 2010, in each test position. The results indicate that the indoor environmental $\mathrm{pH}$ varies in a limited $\mathrm{pH}$ range between 6.5 and 7.0, while the outdoor environmental $\mathrm{pH}$ range is much lower, even though the range is limited as well, between 5.0 and 5.5. The most important feature is the difference at about $1.5 \mathrm{pH}$ units between indoor and outdoor data. Since the indoor environmental $\mathrm{pH}$ is close to the optimal neutral conditions, the systems and procedures currently used by the Palace Museum for controlling indoor environment are working correctly. However, since the outdoor $\mathrm{pH}$ is considered to be too low (too acid) for a proper conservation of Heritage items, ventilation and, in general, the entrance of outdoor air without adequate conditioning should be avoided.

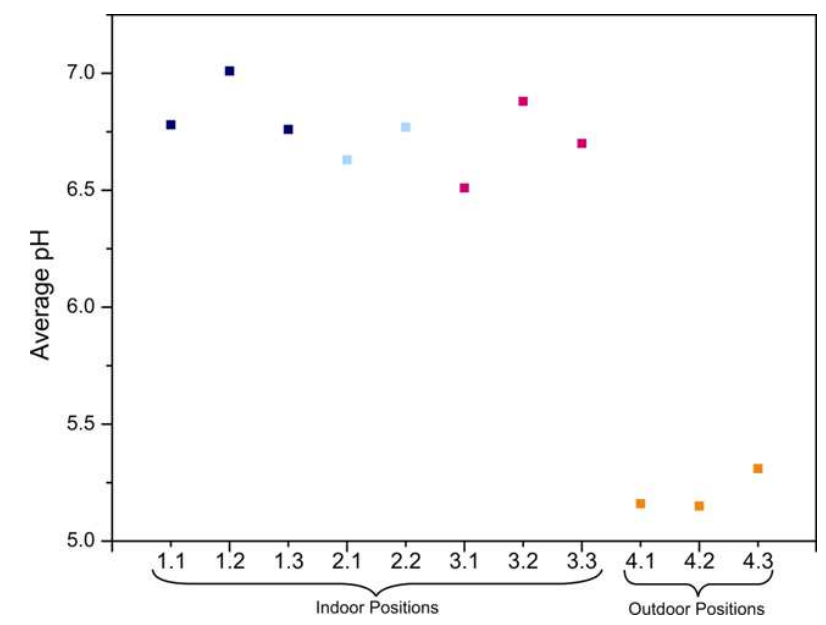

Fig. 7. Average environmental acidity results recorded from June 2010 to December 2010

In Fig. 8 the calculated values of $\Delta \mathrm{pH}$ (maximum variation of all $\mathrm{pH}$ data recorded for a given test position) are plotted. The parameter $\Delta \mathrm{pH}$ is useful to evaluate the changes of environmental $\mathrm{pH}$ sustained by the Heritage items close to a test position. The meaning of $\Delta \mathrm{pH}$ concerns the environmental stability and the risk of acidity shock, which is the origin of chemical degradation of most materials. Although there are neither standards about the environmental $\mathrm{pH}$ nor recommendations on the maximum $\mathrm{pH}$ variations $(\Delta \mathrm{pH})$, it seems reasonable to consider that more than one $\mathrm{pH}$ unit in $\Delta \mathrm{pH}$ is not adequate for proper conservation, and even the $\Delta \mathrm{pH}$ range between 0.5 and 0.8 could be high enough to ensure no risk of acidity shock. Thus, $\Delta \mathrm{pH}$ values at about 0.8 could be considered as the critical threshold. Above such threshold the risk of acidity shock increases dangerously. Some $\Delta \mathrm{pH}$ values in Fig. 8 (test positions 1.1, 1.2, 1.3, 2.1, 3.1 and 3.2) are higher than 0.8 , which could indicate that in such test positions the risk of acidity shock is higher than in the others. However, $\Delta \mathrm{pH}$ values must be interpreted with the average $\mathrm{pH}$ values (Fig. 7). This means that, for instance, a $\Delta \mathrm{pH}=$ 0.8 or higher will indicate a risk of acidity shock if the corresponding average $\mathrm{pH}$ is lower than $6.5(0.5 \mathrm{pH}$ units lower than the theoretical neutral conditions at $\mathrm{pH}=7.0)$. Bearing in mind this criterion, the test position 3.1 (average $\mathrm{pH}=6.50$ and $\Delta \mathrm{pH}=1.55$ ) can be considered as one area under risk of acidity shock. In the same way, the test positions in which $\Delta \mathrm{pH}$ is low but the average $\mathrm{pH}$ is strongly acid (e.g. outdoor test positions 4.1, 4.2 and 4.3) should be considered areas under risk of acidity shock. To sum up, two criteria are stated to define the environmental conditions that enhance the risk of acidity shock: i) average $\mathrm{pH}$ values lower than 6.0 and ii) $\Delta \mathrm{pH}$ values higher than 0.8 .

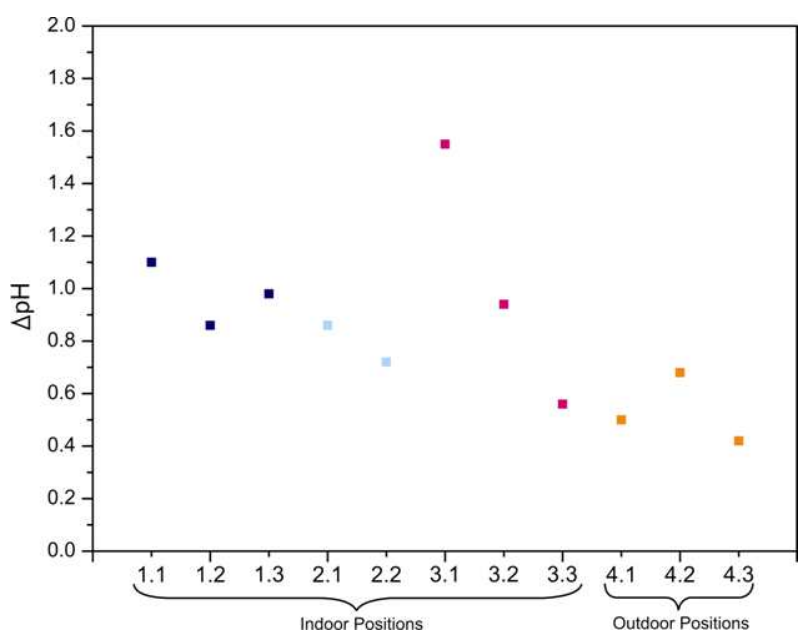

Fig. 8. Variation $(\Delta \mathrm{pH})$ of the environmental acidity results recorded from June 2010 to December 2010

The test positions $3.1,4.1,4.2$ and 4.3 correspond to areas with higher risk of acidity shock. Test position 3.1 in Karmazynowi room is just above a ventilation grid, which explains the variation of acid species introduced from the outdoor air. It is important to note that the other two test positions of the same room (3.2 and 3.3) show good average $\mathrm{pH}$ values between 6.5 and 7.0 , and only the test position 3.3 (corresponding to a small cabinet inside Karmazynowi room not visited by the public) show low $\Delta \mathrm{pH}$ values. These results clearly indicate the contribution of the outdoor air and the visitors on the values of average $\mathrm{pH}$ and $\Delta \mathrm{pH}$ and, hence, on the risk of acidity shock. Fortunately, the areas under acidity risk are limited to some parts of rooms and, of course, to 
the outdoor test positions. In this former case, the low average $\mathrm{pH}$ values are due to the environmental pollution and the high percentages of relative humidity in Wilanów, enhanced by the Vistula River. Regarding the environmental outdoor pollution, it is important to note that the Palace gardens were remodelled during several months. In such works, heavy machines were working for many hours per day just in front of the different façades of the Palace.

3.2. Environmental temperature. Temperature data were obtained from the intensities of the visible absorption at $\lambda=669 \mathrm{~nm}$ of sensors and the calibration curves of Fig. 6 . The optical response of outdoor temperature sensors (T6) was checked with the calibration curve built in the -15 to $+15^{\circ} \mathrm{C}$ temperature range. The optical response of indoor temperature sensors (T5) was checked with the calibration curve built in the 10 to $28^{\circ} \mathrm{C}$ temperature range.

Figure 9 shows the results of average temperature calculated for each test position. Indoor data vary between 17 and $20^{\circ} \mathrm{C}$. In the same room the temperature differences recorded can be explained by orientation. For instance, in Lubomirski room the test positions 1.1 and 1.3 (on the windows curtains) recorded higher temperatures than position 1.2. Position 1.2 is the furthest from windows and, hence, does not receive directly the sun radiation of the Lubomirski South façade. However, in Sypialnia królowej room, the two test positions of this smaller area showed a difference of $0.5^{\circ} \mathrm{C}$, which is negligible. In Karmazynowi room, the average temperature of positions 3.1 and 3.2 is similar, while the temperature of position 3.3 is lower. This can be explained because the test position 3.3 corresponds to a small cabinet in one extreme of the Karmazynowi room, without the visitors influence. Moreover, the cabinet has not a heating system and its environment is permanently in contact with the air of the Karmazynowy room, since there is any door between them.

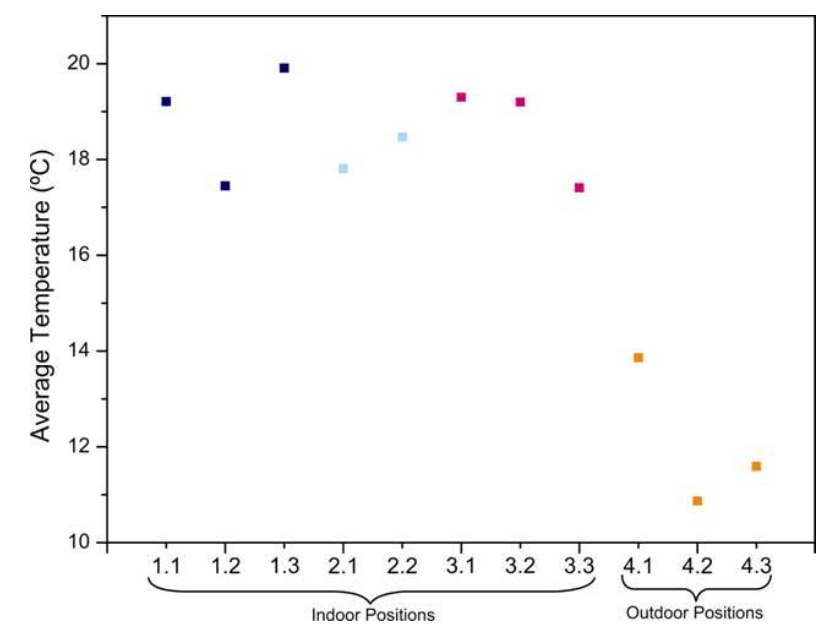

Fig. 9. Average environmental temperature results recorded from June 2010 to December 2010

Concerning the outdoor temperature data recorded, they are much lower and the variations observed are, in general, due to the different orientation. However, the average temper- ature of the test position 4.1 (North façade) is not the lowest. This could be due to the relative protected orientation of such position. The average temperature values recorded in the test positions 4.2 and 4.3 are coherent with their respective orientation and particular characteristics of these positions.

Other thermal parameter evaluated was the maximum temperature variation $(\Delta T)$ in each test position. The meaning of this parameter is the risk of thermal shock to which the Heritage items are exposed. Figure 10 summarises the results obtained for $\Delta \mathrm{T}$ of each test position. Indoor the Palace the values recorded of $\Delta \mathrm{T}$ are at about $15^{\circ} \mathrm{C}$. This can be considered high enough to cause some kind of damage in Cultural Heritage items and, thus, affect their conservation [8]. However, those $\Delta \mathrm{T}$ values were calculated from the values recorded during a long period of time (6 months) and, hence, the real temperature variation occurred slowly and progressively. If such temperature variation takes place suddenly in a short period of time, they would be really dangerous. It is important to note that during the last week of September and the first one of October, the heating system of Wilanów Palace had a failure that originated the very low temperatures recorded. These data contributed in the corresponding calculation of $\Delta \mathrm{T}$ for values as high as $15^{\circ} \mathrm{C}$. Therefore, apart from the failure mentioned, no risk of thermal shock is expected indoor the Palace Museum.

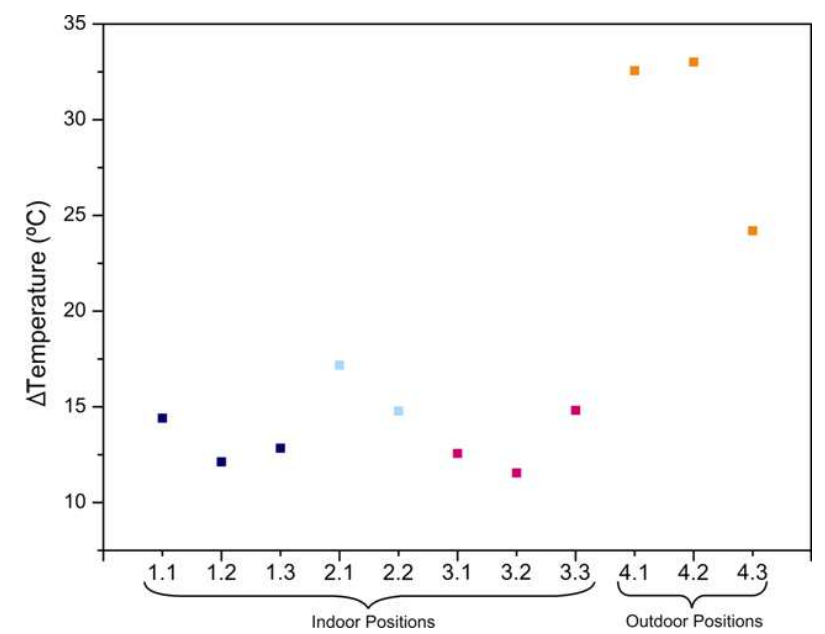

Fig. 10. Variation $(\Delta T)$ of the environmental temperature results recorded from June 2010 to December 2010

As far as the outdoor temperature concerns, the calculated values of $\Delta \mathrm{T}$ are as high as $32^{\circ} \mathrm{C}$ (Fig. 10), which can be explained by the progressive falling down of temperatures from summer to winter. The value of $\Delta \mathrm{T}$ in the test position 4.3 is the lowest among the values of the outdoor positions. Thus, this position is thermally the most stable, due to its South orientation that prevents, at least partially, for extremely low temperatures compared with the test positions in other oriented façades.

\section{Conclusions}

Data of environmental acidity recorded by means of optical sol-gel sensors indicate that indoor acidity is close enough to 
the theoretical neutral conditions and, hence, is adequate for proper conservation of Heritage items of the Palace Museum of Wilanów. Outdoor environmental $\mathrm{pH}$ values are considerably lower than those of indoor values. Such outdoor acidity values are stable and more than $1.5 \mathrm{pH}$ units lower than the average indoor $\mathrm{pHs}$. The high percentages of relative humidity of the Wilanów area favour the formation of acid substances when gaseous acids pollutants are present. Such humidity also ensures the correct response of sensors, since the sensitive phase of sensors reacts with the simultaneous combination of humidity and acid pollutants.

Temperature sensors have demonstrated to be sensitive enough to detect small temperature differences even in the same room. High temperature variations have been detected throughout the long period of data recording, which have been attributed to the natural change of climate from summer to winter and to an eventual failure of the heating system that took place at the end of September 2010. Natural falling down of outdoor temperature was also recorded by sensors.

Acknowledgements. The authors wish to thank the management and the staff personnel of the Wilanów Palace Museum for their cooperation, especially during installation and periodic recording of data from sensors.

Likewise, they are indebted to Prof. Z. Hensel, Polish leader of the bilateral project that made possible this work, as well as to the other participants from the Polish Academy of Sciences, Prof. Z. Kobylinski, U. Kobylinska and D. Wach.

Financing of the bilateral project PAN-CSIC ref. 2008PL0021, Program Consolider Ingenio 2010 CSD-TCP ref. 2007-00058 and Program Geomateriales ref. CM S-2009/Mat1629, are acknowledged.

J. Pena-Poza acknowledges a contract to the Program Consolider Ingenio mentioned. T. Palomar acknowledges a pre- doctoral FPU grant to the Spanish Ministry of Science and Innovation.

\section{REFERENCES}

[1] M.A. Villegas, "Indicadores cromáticos de la acidez ambiental", in: Jornadas Nacionales sobre Restauracion y Conservacion de Vidrios. La Granja de San Ildefonso, pp. 145-159, Fundation Centro National del Vidrio, Sergovia, 2000.

[2] M. Garcia-Heras, N. Carmona, C. Gil, and M.A. Villegas, "New optical sensors for monitoring acid environments in preventive conservation", Coalition. CSIC Thematic Network on Cultural Heritage. Electronic Newsletter 7, 5-8 (2004).

[3] M.A. Villegas, "Procedimiento de encapsulamiento de colorantes organicos en un material solido para la produccion de sensores con respuesta optica, para la medida de la acidez, basicidad o $\mathrm{pH}$ de entornos gaseosos, o liquidos, o mixtos solidos/liquidos", Patent P200602403, CSIC, Spain (2006).

[4] N. Carmona, M.A. Villegas, and J.M. Fernandez Navarro, "Optical sensors for evaluating environmental acidity in the preventive conservation of historical objects", Sensors and Actuators A 116, 398-404 (2004).

[5] M. Garcia-Heras, K. Kromka, J. Faber, P. Karaszkiewicz, and M.A. Villegas, "Evaluation of air acidity through optical sensors", Environmental Science and Technology 39, 3743-3747 (2005).

[6] N. Carmona, E. Herrero-Hernandez, J. Llopis, and M.A. Villegas, "Novel sol-gel reversible thermochromic materials for environmental sensors", J. Sol-Gel Science and Technology 47, 31-37 (2008).

[7] N. Carmona, M. Garcia Heras, E. Herrero, K. Kromka, J. Faber, and M.A. Villegas, "Improvement of glassy sol-gel sensors for preventive conservation of historical materials against acidity", Boletin Sociedad Espanola de Ceramica y Vidrio 46, 213-217 (2007).

[8] D. Van der Reyden, "Paper documents", Storage of Natural History Collections: a Preventive Conservation Approach 1, 327353 (1995). 